\title{
THE SMEs KNOWLEDGE MANAGEMENT: Professional Risk Assessment Using A KBS
}

\author{
Rosu, S.M.; DragoI, G.; Guran, M. \& Dragomirescu, C.
}

Abstract: How can experts from different activity domains structure and share what they know efficiently? How can experts integrate their knowledge more productively? To answer these questions we propose in this paper a feasible solution: a knowledge management framework as support for a knowledge based system (KBS) development in the small and medium sized enterprises (SMEs). Therefore, this work analyse the state of art of the SMEs knowledge. In addition, in this paper we describe the professional risk assessment as part of risk management process and as essential part of SMEs business and we present how can be a KBS built and used to assess the professional risk at the SMEs level.

Key words: knowledge base, knowledge based system, knowledge management, professional risk assessment, SME
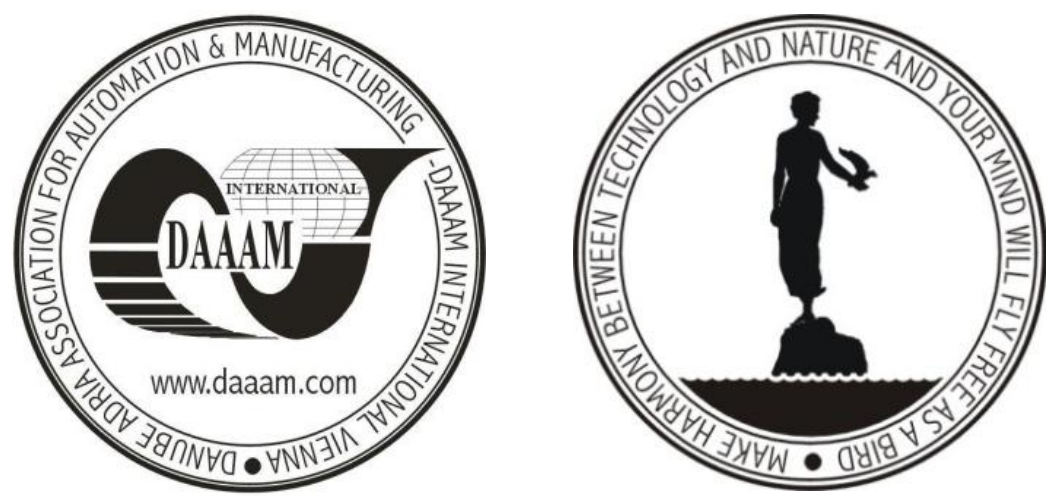

Authors' data: PhD. Student Rosu, S[ebastian] M[arius]*; Prof. Dragoi, G[eorge]**; Prof. Guran, M[arius]**; Assoc. Prof. Dragomirescu, C[ristian]***, *Special Telecommunications Service, 323A Splaiul Independentei, Sector 6, 060044, Bucharest, RO, **UPB, FILS, PREMINV Research Center, 313 Splaiul Independentei, Sector 6, 060042, Bucharest, RO, *** UPB, Mechanical Engineering Department, 313 Splaiul Independentei, Sector 6, 060042, Bucharest, RO, sebastianrosu@stsnet.ro, gdragoi@mix.mmi.pub.ro, mguran@mix.mmi.pub.ro, cristian_dragomirescu@yahoo.com

This Publication has to be referred as: Rosu, S[ebastian] M[arius]; Dragoi, G[eorge]; Guran M[arius] \& Dragomirescu, C[ristian] (2010). The SMEs Knowledge Management: Professional Risk Assessment Using a KBS, Chapter 62 in DAAAM International Scientific Book 2010, pp. 709-724, B. Katalinic (Ed.), Published by DAAAM International, ISBN 978-3-901509-74-2, ISSN 1726-9687, Vienna, Austria DOI: $10.2507 /$ daaam.scibook.2010.62 


\section{Introduction}

The market situation of the European countries is the following: 99\% of companies in the EU are small and medium sized enterprises (SMEs) - companies with a maximum of 250 employees and a maximal turnover of $€ 50$ million. In the European Union (Europe have 23 million SMEs and 41000 large companies) SMEs employ more than $65 \%$ of all employees. During past years, SMEs have created $80 \%$ of the new jobs in the EU (IP/08/1003, Brussels, $25^{\text {th }}$ June 2008).

The SMEs research development activities, products development, new technologies implementation, etc., presupposes knowledge and assumption of multiple risks. As a result of a new product development paradigm, there is a greater need for software tools to risk estimation. The risk evaluation sustains SMEs in the uncertainties elimination in the development strategy and management policies. Estimation, evaluation and control of the occupational risk represent prerequisites for grounding and for a continual support of the decision that has been previously taken on occupational safety in a working system (Vasilescu et al., 2008). Risk management presumes the identification, assessment and control of risks that influence the organizations success and the efficiency of decisions making (Doval \& Stoica, 2008).

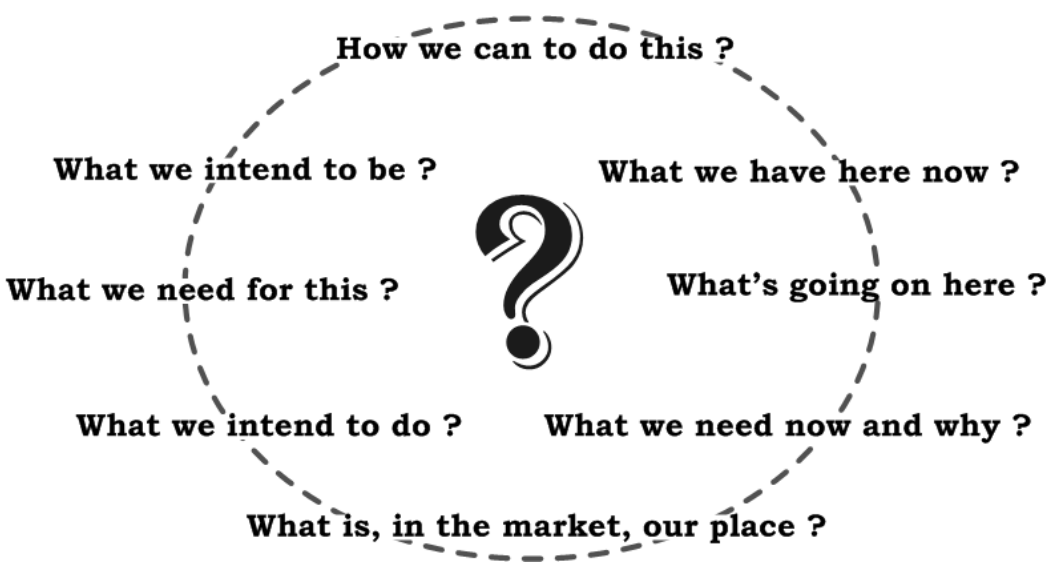

Fig. 1. The essential questions at the SMEs level

However, in the last time, a lot of research in the field of knowledge management is dedicated to large companies or international concerns and the small and medium-sized enterprises were forgotten. This is the main reason why in this paper analyze the SMEs knowledge and knowledge management (KM), the risk management process and the professional risk assessment as essential part of SMEs business, the knowledge bases built and use to assess the risk at the SMEs level.

Nowadays, enterprises tend to differentiate themselves from what they know (intellectual capital) and from how they use knowledge. The interest for knowledge within enterprises begins with identification that the value of market of several enterprises is much larger than the value of their own physical patrimony (equipments, facilities etc.). Anyway, before start to collect and use knowledge, the companies need to have a good defined answer at the essential SMEs questions shows in figure 1 . 


\section{The SMEs knowledge and knowledge management}

Knowledge exists in the mind of people and circulates within organizations (Nonaka \& Takeuchi, 1995). For all companies KM and innovation plays an important role (Porter, 2001). Many of KM initiatives are implemented in large companies but in the last years there is a shift towards small and medium-sized enterprises (Fink \& Ploder, 2006). According to some studies SMEs need a simple framework to organize their key knowledge processes: knowledge identification, knowledge acquisition, knowledge distribution and knowledge preservation (Fink \& Ploder, 2007; Ploder \& Fink, 2007). The key knowledge processes (KKPs) for SMEs identified by us are presented in figure 2 (Rosu et al., 2009).

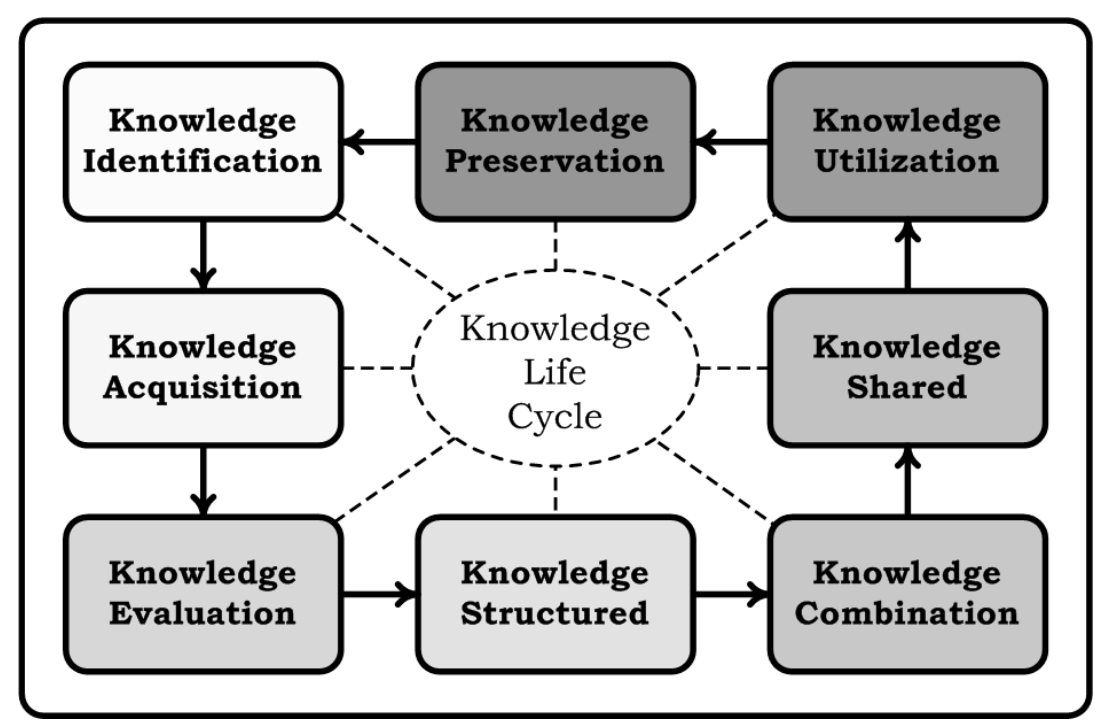

Fig. 2. The key knowledge processes (KKPs) for SMEs

For SMEs it's necessary that the advantages of $\mathrm{KM}$ are clear and the implementation is easy otherwise they will continue to focus on their traditional way of working (Nunes et al., 2006). There are four different roles of knowledge in SMEs business (see figure 3), (Heinrich \& Lehner, 2005):

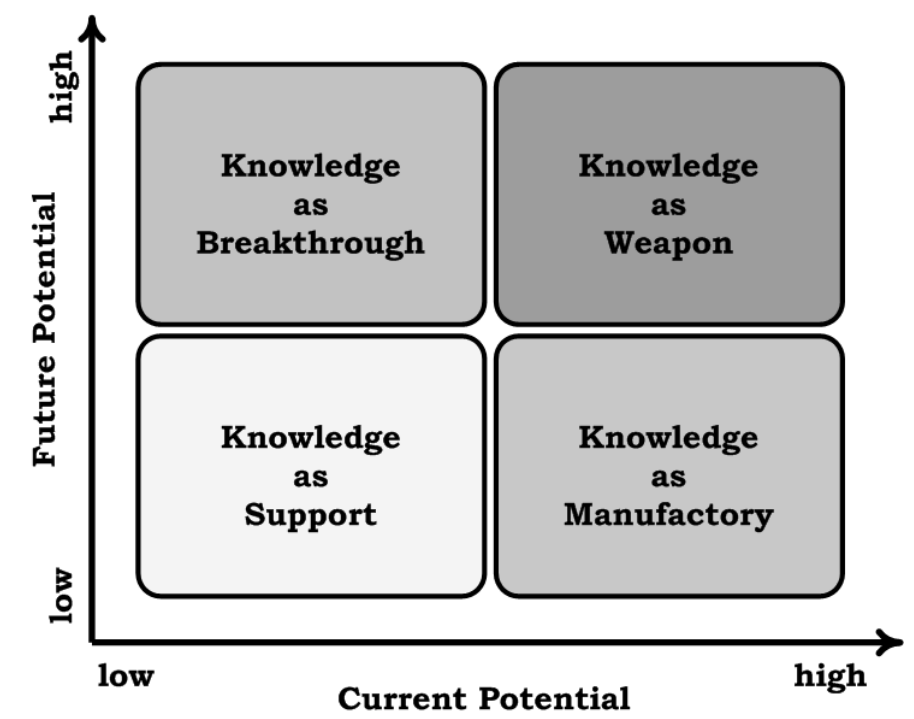

Fig. 3. The knowledge roles in SMEs business 
1) Knowledge as support: there is a low current strategic position of knowledge and in future too.

2) Knowledge as manufactory: knowledge plays now an important role but the importance will decrease in future.

3) Knowledge as breakthrough: in future knowledge will play a very important role for the business still it does not.

4) Knowledge as weapon: knowledge is important and the importance will increase in future.

Generally, in some SMEs activity sectors, the knowledge generate capacity exceeds the human records and process capacity, which lead to a super sized knowledge offer. In this way can be generated an inefficacy at the organizational and personal level.

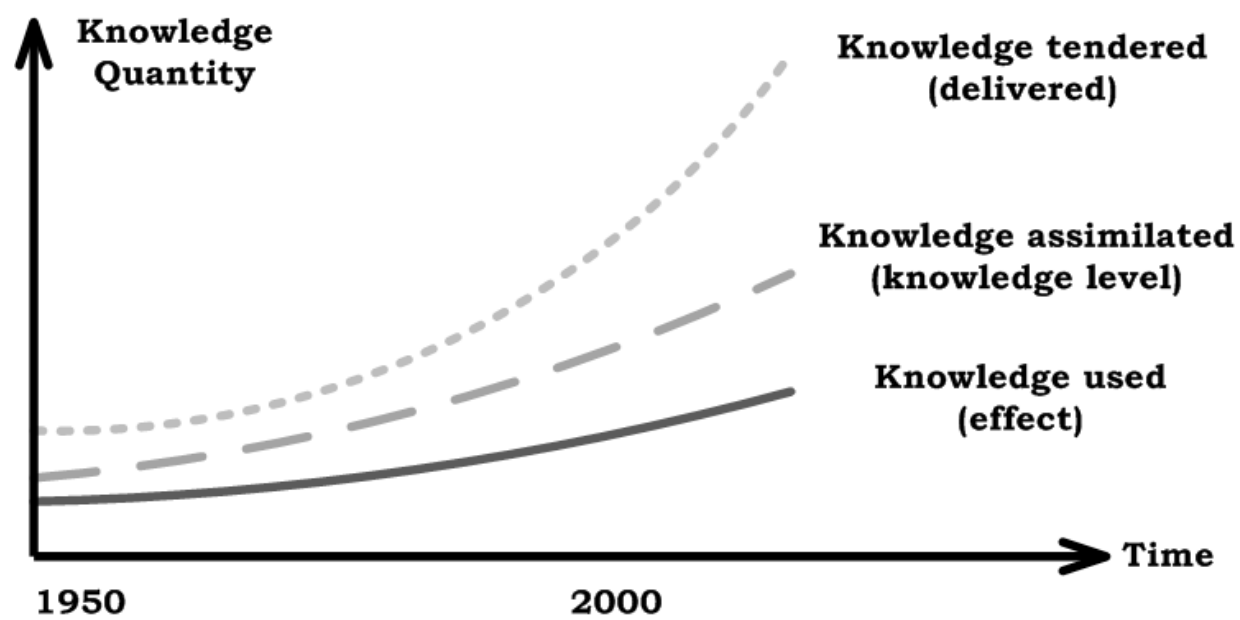

Fig. 4. Knowledge flow vs. knowledge used in SMEs

Figure 4 shows the relationship among knowledge production, knowledge assimilated and the knowledge uses effect. This figure reflects the three essential trends that characterize the new knowledge society and can influence some SMEs activities (Rosu et al., 2009):

1) Knowledge offer increase;

2) Knowledge assimilated increase, but in a much slow rhythm;

3) Maintaining an almost constant level for knowledge used.

Short, medium and long term knowledge in handling industrial purposes research will focus on three main directions:

1) Knowledge capitalization;

2) Knowledge formalization;

3) Knowledge use.

The main studies are identified three important distinctions of types of knowledge that has been used (Rosu et al., 2006):

1) The explicit knowledge - which can be expressed in words and numbers; they can easily be communicated and distributed in the form of data, scientific formulas, codified procedures or universal principles.

2) The tacit knowledge - that are very personal and difficult to formalized, dependent on experience and individual characteristics. 
3) The implicit knowledge - stored in the entities that depend on the practical context - products, technologies, processes, etc.; the value of knowledge is manifested in physical goods and services, the intellectual products (patents and licenses), processes (structural capital) and people (intellectual capital).

At the enterprise level the knowledge could be found to individual, group or external resources. Professional qualifications, personal experiences, capacity to transform information's in knowledge constitute the individual resources. Patent acts, models, concepts, enterprise culture and management form the group resources. Individual and group resources totality represents the enterprise internal resources. Relations set of external resources with client, suppliers and partners, product and services credibility, offering quality. Tacit or explicit knowledge transfer between these resources and knowledge conversion from a resource to other determines value creation (Rosu et al., a2008). Figure 5 shows how business value is added when the volume and quality of knowledge from the company grows.

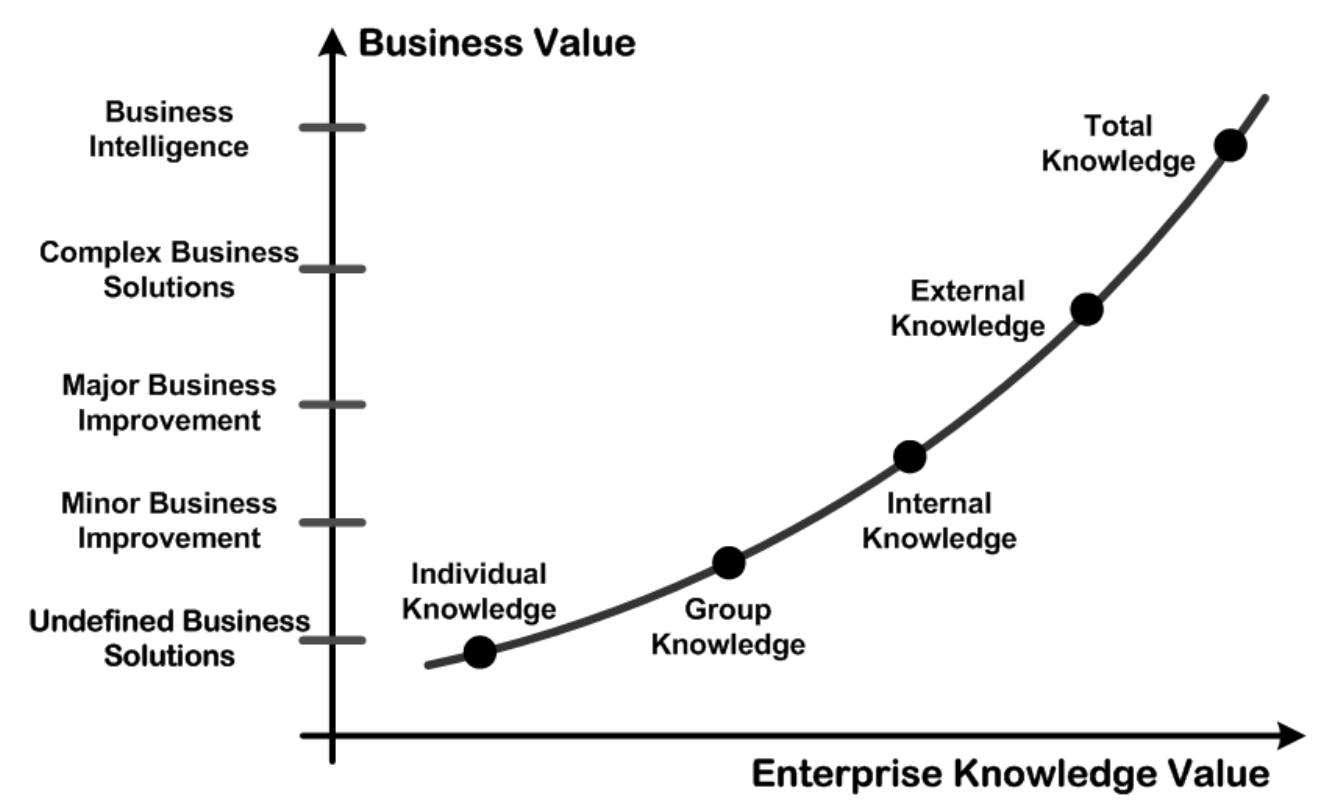

Fig. 5. Business value vs. knowledge value in SMEs

Knowledge management is the process that is organization and coordination of knowledge from the knowledge of the organization. This process involves (see in figure 6 the key knowledge management processes - KKMPs):

1) Knowledge clustering - the kinds of knowledge from the sources of the organization, the processes up to formation of internal memory;

2) Knowledge storage - which aims to store knowledge in the knowledge infrastructure of the organization in terms of efficiency;

3) Knowledge classified - for evaluating and granting priorities that reflect the quality of knowledge and the adequacy requirements processes;

4) Knowledge selection - which allows the user to use certain criteria for identifying the most appropriate knowledge;

5) Knowledge dissemination - that knowledge stored in various forms (tacit, explicit or implicit) are accessed by all members of the organization and even stakeholders - customers, suppliers, etc. 




Fig. 6. The key knowledge management processes (KKMPs) for SMEs

The knowledge of the enterprise contains the sharing knowledge of each individual (Dragoi et al., 2007). For increase the knowledge in SMEs for an efficient management of the intellectual capital and to improve the business value, we define a KM framework in ten steps: obtains and uses, learn and contribute, evaluates, sustain, support, exchange, combination, transfer, recovery and discharge (see figure 7), (Rosu et al., 2009):

1. The step obtain and use is well known within organizations. People always seek information and use them later to solve their problems, to take decisions or to create new products. Therefore, new technologies (e.g. Intranet/Internet/Extranet) allow that the large amount of information that flows within organizations can be correctly managed.

2. The step learn and contribute are relatively new for organizations. For example, it has been difficult to convince employees to contribute to the organization's knowledge base. New technologies have helped companies easily organize, send and transfer certain types of information. However, the employee has seen this facility as a threat for his/hers own job security. The most difficult task is to convince individuals that their contribution will give return to their organization as well as to themselves.

3. The step evaluates indicate that the organization should define its own necessary knowledge for its mission and classify its own currently intellectual capital. In other words, the knowledge manager does more than organize the content in system on-line; he/she should understand and foresee the community's needs.

4. The step sustain or maintain should assure that the future intellectual capital would maintain the organization viable and competitive. Organizations tend to build their own intellectual capital through their relationships with customers, employees, suppliers etc. The knowledge manager should also be responsible for the maintenance of the organizations knowledge base.

5. The step support can be used for the continuous improvement of the product design process.

6. The step exchange represents an intelligence and creativity combination of organization employees to find better solutions to their problem. Knowledge exchange involves interaction between decision makers and researchers or project development teams and results in mutual learning through the process of 
planning, disseminating, and applying existing or new research in decisionmaking.

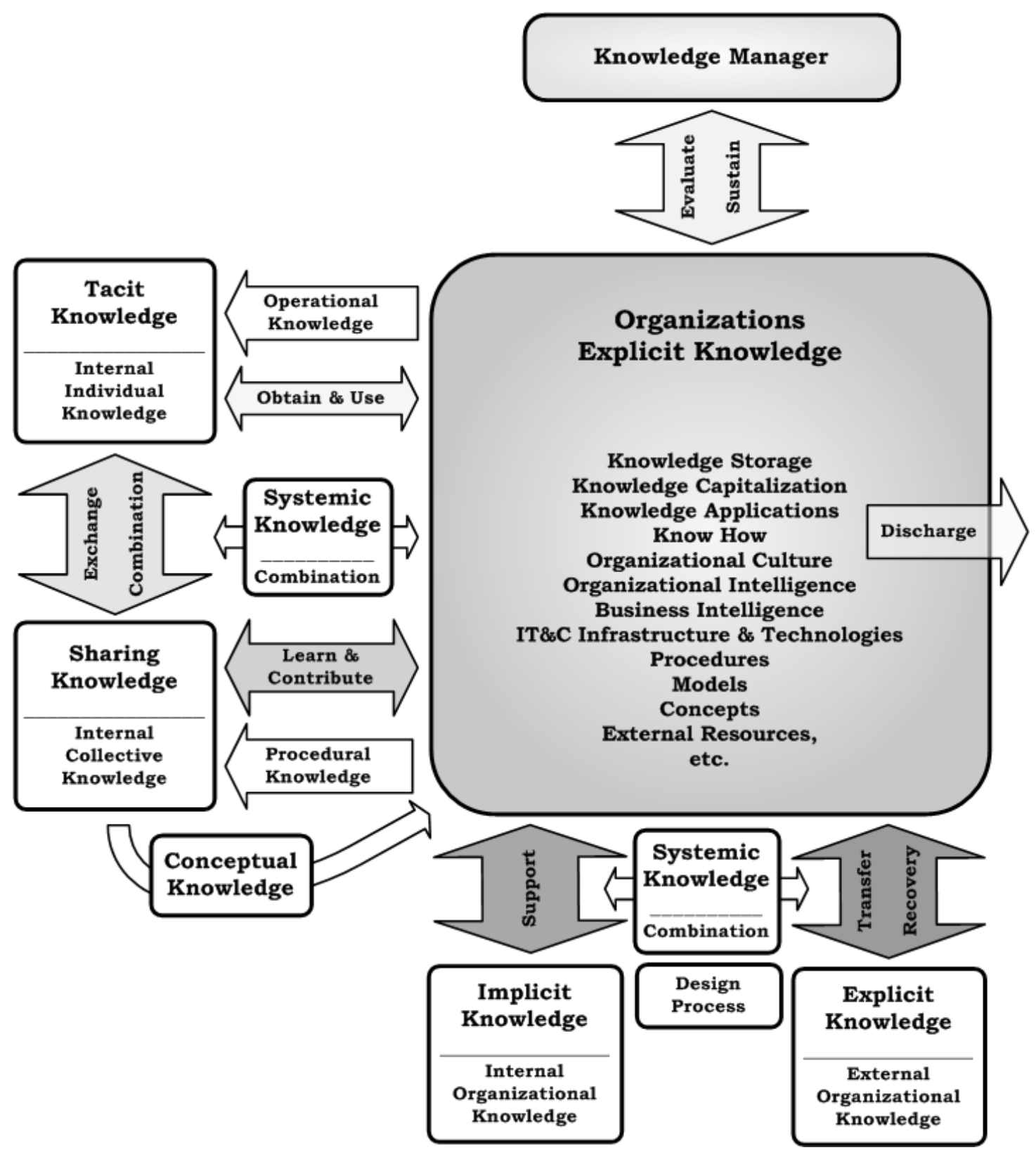

Fig. 7. A knowledge management framework for a KBS development in SMEs

7. The step combination can be making by means of the Industrial Informatics Systems or Knowledge Work Systems.

8. The step transfer realized by teaching process, e-learning and simulations. At the organization level the knowledge could be found to individual or group (collective) resources.

9. The step recovery utilized when the organization must re-create knowledge that disappears because documentation isn't adequate or experts don't pass along knowledge before they leave.

10. The step discharge excludes any useless knowledge from the organizations knowledge base. However, some knowledge can be more valuable if transferred outside the organization. 
Rosu, S.M.; Dragoi, G.; Guran, M. \& Dragomirescu, C.: The SMEs Knowledge ...

\section{Professional risk assessment as part of risk management process in SMEs}

Commonly, the risk management process (RMP) includes three phases:

1) Risk identification;

2) Risk analyses;

3) Risk feedback.

In the SMEs activities risk eludes probability to not perform the establish objectives such as (Rosu et al., b2008):

1) Performance - quality standards failure;

2) Schedule - execution terms failure;

3) Costs - budget exceeding.

Risk factors are all factors that can have probability to deviate a plan. Risk management process is an important component of a successful project development process with informational system support. Risk is the net negative impact of the exercise of vulnerability, considering both the probability and the impact of occurrence (EASHW, a2007). Risk management is the process of identifying risk, assessing risk, and taking steps to reduce risk to an acceptable level (see the RMP in figure 8), (Rosu et al., b2008). The RMP should not be treated primarily as a technical function carried out by the IT experts who operate and manage the IT system, but as an essential management function of the organization.



Fig. 8. The risk management process (RMP)

In EU countries there is an experience and good practice both in classifying, identifying, and evaluating risks and in eliminating and reducing those (Botezatu et al., 2008). Among others we can mention that at SMEs level, a lot of attention is paid to: air quality (ventilation systems), pressure equipments, elevators, lifting equipments and accessories, noise, construction sites, shipyards, illumination, 
electricity, individual protection equipments, explosives, extraction of fat using flammable substances, fires, fixed refrigeration systems, heat systems, machinery, flammable liquids or liquefied gases, chemical hazard, depots, air cooling towers, etc. (Yule et al., 2007).

The way SMEs approach the topic of risk assessment is strongly influenced by the structure and strengths of the particular SME, but there are some characteristics that are applicable to most if not all SMEs, as follows (Baetens, 2008):

1) Informal social dialogue - in most SMEs, social dialogue is conducted in a very informal way. In most of them there are no formal consultation bodies or procedures. The social dialogue in SMEs is a continuous, informal interaction between employer and employees and also among employees. Many SMEs don't have, and don't need, formal consultation bodies or procedures to identify problems or pinpoint risks. The problem and the solution will be discussed on the shop floor.

2) Employer works with employees - an enormous advantage for most SMEs is the fact that the employer works alongside the employees. This means they can see the risks in the workplace and operations first hand and will be more likely to take measures to reduce or eliminate risk. These measures can include important innovative changes or simply small changes with great effectiveness for the safety of workers and employer. With this kind of operation, risk assessment is a continuous, informal process.

3) Flexibility - flexibility is the key for SMEs. Employer and employees are often required to multi-task in a constantly changing environment. They are highly adaptable. This also means that workers have a good knowledge of how their company works, and most of the workplace risks. This flexibility among staff will affect the way the risk assessment is carried out.

4) Fast decision-making process - another advantage of SMEs is the fast decisionmaking process. In a larger company when one wants to introduce changes, it is usually necessary to consult several hierarchies of managers. In an SME with a flat hierarchy, the employee can go directly to the right person and make a proposal. This saves both time and energy.

5) Familiar atmosphere - employees are working for the company but are also ready to be mutually supportive and to help each other if necessary. The willingness to support colleagues creates a very special atmosphere in the company between workers and between employer and employees. This makes it easier for employees to correct one another and to educate one other on risk assessment.

6) Easy communication - the traditional informal communication and the direct and personal relationships at all levels of an SME facilitate rapid adaptation of change and a better anticipation of risks. These positive elements create a sound basis for carrying out a risk assessment that is adapted to the needs of the company.

A hazard is anything that has the potential to cause harm. Hazards can affect people, property, processes; they can cause accidents and ill-heath, loss of output, damage to machinery, etc. workplace accidents and professional illnesses mustn't be perceived only as fatality, as it is more lucrative to consider them as a malfunction of 
the processes taking places in SMEs (Botezatu et al., 2008). Occupational risk refers to the likelihood and the severity of an injury or an illness occurring as a result of exposure to a hazard. The main aim of occupational risk assessment is to protect workers health and safety. Risk assessment helps to minimize the possibility of the workers or the environment being harmed due to work-related activities. It also helps to keep your business competitive and effective. Professional risk can be assessed in seven steps, as presented in figure 9 .

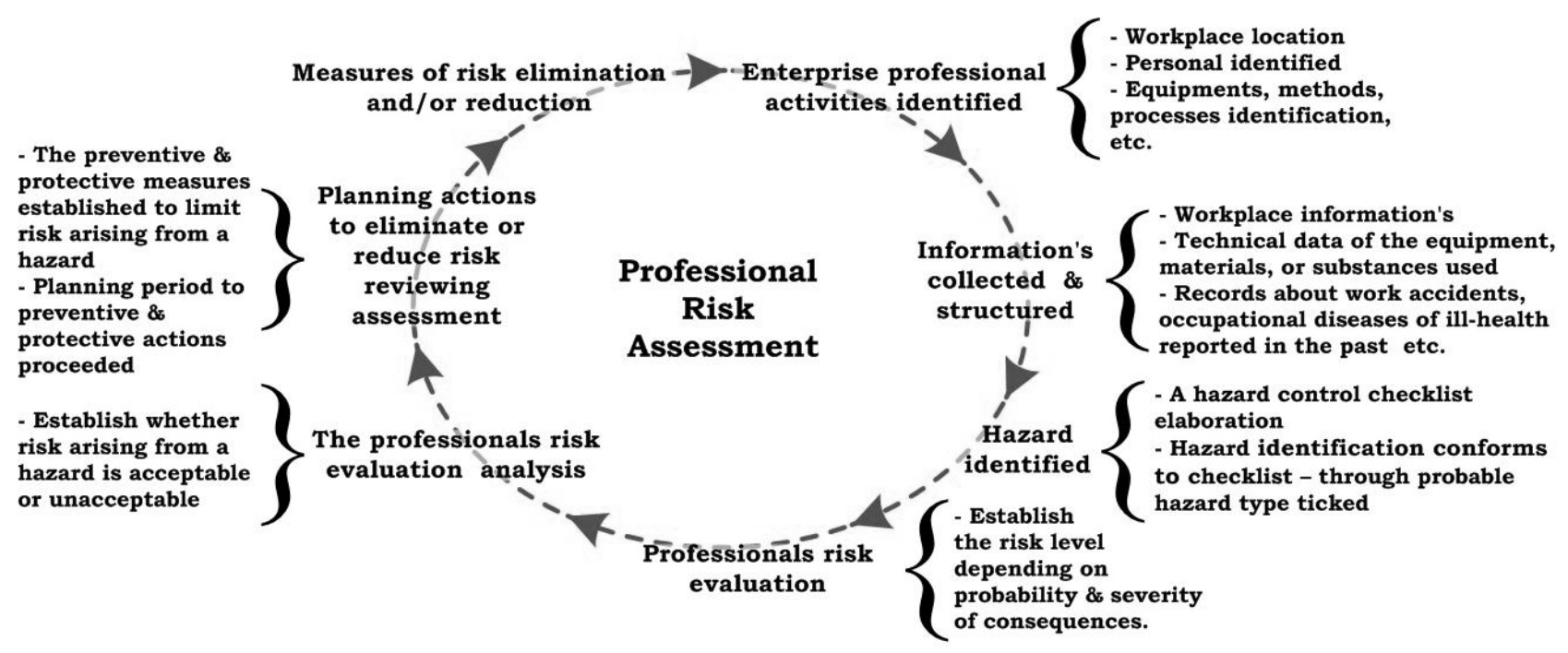

Fig. 9. The professional risk assessment (PRA) steps

But, why is Professional safety and health an essential part of good SMEs business? Professional safety and health (EASHW, b2007):

- Helps demonstrate that a business is socially responsible;

- Protects and enhances brand image and brand value;

- Helps maximize the productivity of workers;

- Enhances employees' commitment to the business;

- Builds a more competent, healthier workforce;

- Reduces business costs and disruption;

- Enables enterprises to meet customers' OSH expectations;

- Encourages the workforce to stay longer in active life.

Under health and safety laws, all employers must carry out regular risk assessment (EASHW, a2007). To assess professional risk at the workplace we need to know:

- Where the workplace and/or the jobs performed are located and who works there: pay particular attention to those for whom occupational hazard may be more severe than usual, such as pregnant women, young workers or workers with disabilities; remember also about part-time workers, subcontractors and visitors, and employees who work off-site (including drivers, those visiting clients' or customers' homes, etc.);

- What work equipment, materials, and processes are used;

- What tasks are performed; 
- What the potential consequences of existing hazards are;

- What protective measures are used;

- What accidents, occupational diseases and other occurrences of ill health have been reported;

- What legal and other requirements are related to the workplace, etc.

\section{A knowledge based system to professional risk assessment in SMEs}

At PREMINV Research Center, University "POLITEHNICA" of Bucharest, we implemented some of the KBS modules for risk assessment in various professional fields, system able to provide at the SMEs level the original KM framework (proposed in figure 7) implementation. A first KBS module is focused on professional risk assessment for a Cars Repair Workshop.

To identify hazards at the workplace we prepared a General Hazard Checklist (see Table 1). This list can be extended according to specific facilities. Note that, correct identification of hazards involves active involvement of all employees in the process of gathering information.

\begin{tabular}{|c|c|c|c|}
\hline No. & Hazard & Yes & No \\
\hline \multicolumn{4}{|c|}{ Does the hazard exist at the workplace? } \\
\hline 1 & Are flat surfaces (floor, inspection pit, etc.) regularly cleaned? & & \\
\hline 2 & Are employees obliged to clean the workplace? & & \\
\hline 3 & $\begin{array}{l}\text { Are flat surfaces (floor, inspection pit in service station, etc.) paint } \\
\text { resistant from substances that are used (e. g., oil, diesel, petrol)? }\end{array}$ & & \\
\hline 4 & Is the inspection pit safely covered after work? & & \\
\hline 5 & $\begin{array}{l}\text { Is the inspection pit suitably marked or surrounded with handrails to } \\
\text { prevent people from falling down? }\end{array}$ & & \\
\hline 6 & $\begin{array}{l}\text { Are there marked (e. g., on the floor) ways for cars to enter the } \\
\text { service station? }\end{array}$ & & \\
\hline 7 & $\begin{array}{l}\text { Are there measures implemented to avoid injuries while working on } \\
\text { bodywork (e. g., welding, grinding, painting)? }\end{array}$ & & \\
\hline 8 & $\begin{array}{l}\text { Are suitable protective measures being used to prevent or reduce } \\
\text { exposure to dust and other small parts (e. g., during grinding, } \\
\text { welding, painting)? }\end{array}$ & & \\
\hline 9 & Do workers wear non-slipping shoes? & & \\
\hline 10 & $\begin{array}{l}\text { Are there defined safety rules for assembly work (e. g., bodywork, } \\
\text { engine)? }\end{array}$ & & \\
\hline 11 & $\begin{array}{l}\text { Are there defined safety rules for work with petrol tanks (e. g., } \\
\text { repairing)? }\end{array}$ & & \\
\hline 12 & $\begin{array}{l}\text { Are there defined safe routings or measures to avoid falling parts } \\
\text { from a vehicle (e. g., when a car is lifted)? }\end{array}$ & & \\
\hline 13 & $\begin{array}{l}\text { Are there protective guards to eliminate contact of workers with } \\
\text { rotating parts (e. g., when balancing a dynamic wheel)? }\end{array}$ & & \\
\hline 14 & $\begin{array}{l}\text { Are measures implemented to avoid workers being caught by rotating } \\
\text { parts (e. g., when an engine set up)? }\end{array}$ & & \\
\hline & $\ldots \ldots \ldots \ldots \ldots$ & & \\
\hline \multicolumn{2}{|c|}{ Answer sum: } & & \\
\hline
\end{tabular}

Tab. 1. Hazard Checklist 
Rosu, S.M.; Dragoi, G.; Guran, M. \& Dragomirescu, C.: The SMEs Knowledge ...

For each YES answer in the general list is given 0 points and for each answer NO is given 1 point. Depending on the total score obtained and taking into account the probability and severity of consequences risk arising from hazards are evaluated it may be small, medium or high.

Using expert systems generator VP-Expert (we used the expert system generator - VP-Expert version 2.1, by Brian Sawyer, Educational Version, distributed by Paperback Software International) and based on General Hazard Checklist we built the knowledge base CARREP.KBS (see figure 10).

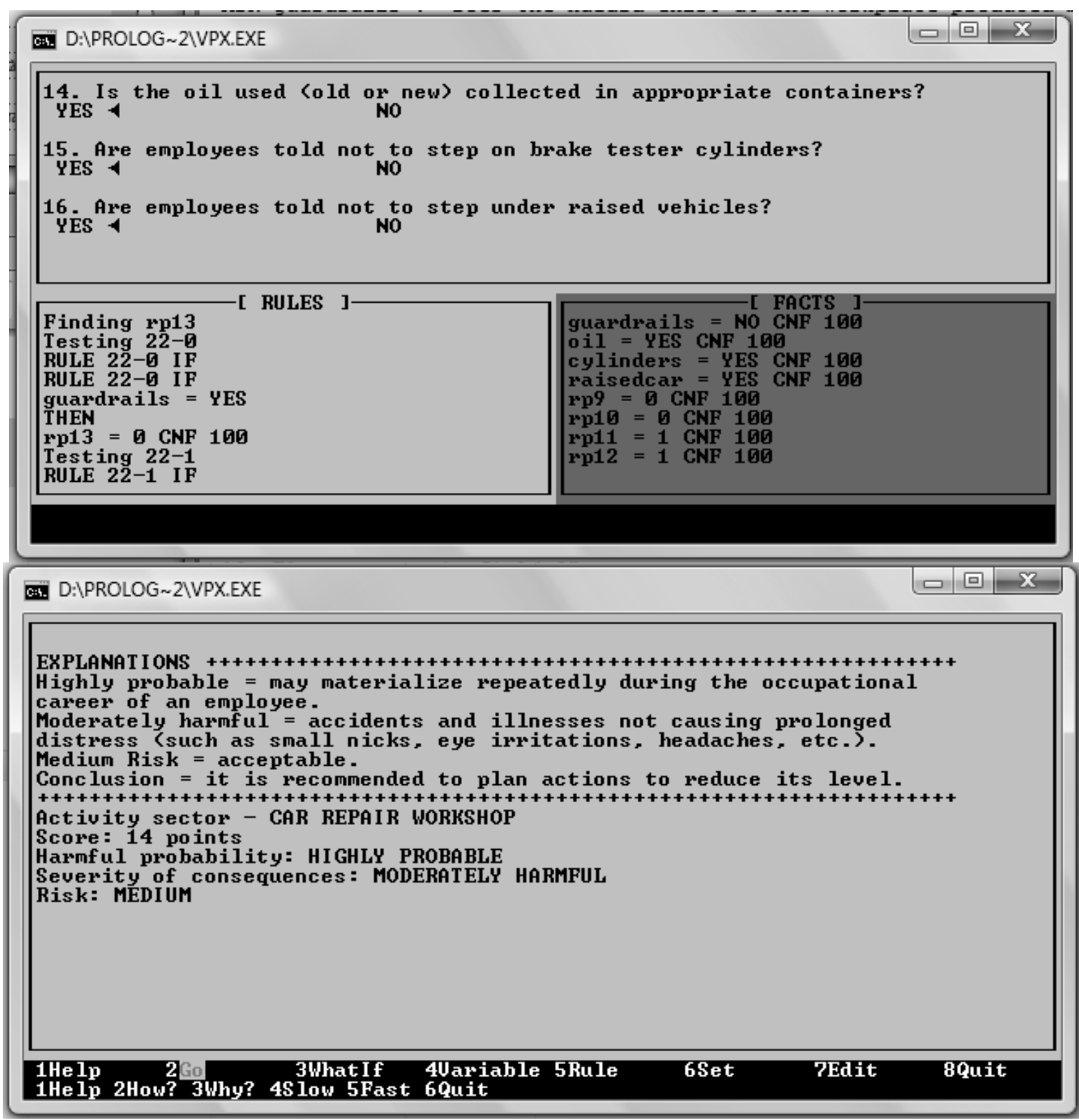

Fig. 10. The CARREP.KBS knowledge interrogation and shows results

The knowledge base rules are following: rules for awarding points variables, rules for calculation of the partial scores and total score and rules for assessment of probability and severity of consequences, and risk arising from hazards in accordance with the total score obtained. To achieve the KBS professional assessment of risk we used the method of representation of knowledge production rules. 
After querying the knowledge base will be displayed to evaluate the outcome of risk assessment conclusion and explanations on the likelihood and severity of injury in terms of consequences (see figure 10).

We considered the risk level depending on probability and severity of consequences as follows: small risk, medium risk and high risk and high risk are unacceptable and small and medium risks are acceptable (see figure 11).

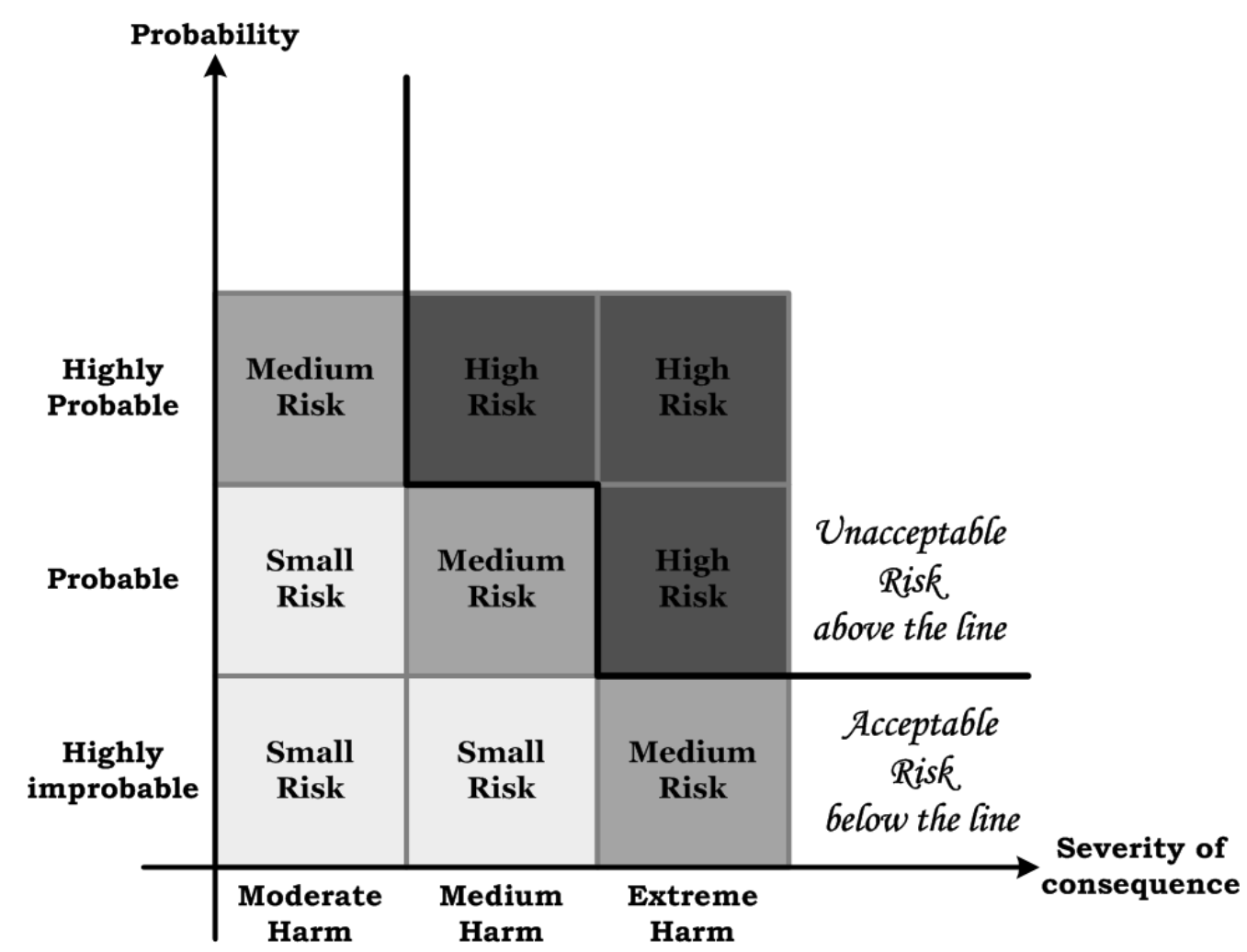

Fig. 11. The risk evaluation based on probability and severity of consequence

In general, if the risk is assessed as unacceptable (height) reduction actions must be taken immediately. If risk is assessed as acceptable (average) is recommended plan of action to reduce or necessary to ensure that it will remain at the same level (in case of risk assessed as small).

Measures of prevention and protection to be implemented in the organization are to eliminate or reduce to a minimum the danger by organizational measures, or use of collective protection equipment suitable for individual protection. To reduce the risk it is necesary to take preventive measures (EASHW, a2007), such as:

- Maintaining flat surfaces, floor, inspection pit, etc., safe and non-slippery; cleaning work area regularly.

- Cleaning thoroughly after grinding, painting, etc.

- Using appropriate material (non-absorbing liquid substances) for flat surfaces.

- Using correct procedures when pouring oil from a storage barrel and collecting used oil into appropriate barrel; cleaning oil off the floor.

- Wearing protective non-slipping shoes.

- Covering the steps into the inspection pit with non-slipping material.

- Never stepping under raised vehicles. 
- Never stepping into a closed inspection pit in a service station.

- Keeping inspection pits in service station covered after work.

- Keeping electrical, hydraulic and pneumatic lines out of people's way.

- Indicating fixed places for working tools, to be used during work and after work.

- Marking (e. g., on the floor) ways for cars and transport routes.

- Ensuring correct control and placement of lifting mechanism arms; not putting hands into moving parts.

- Ensuring that all activities are performed by well-trained staff; respecting all required safety procedures.

- Using only recommended safe tools for work with batteries.

- Ensuring proper ventilation to avoid creation of explosive mixtures of various vapours and liquids. Never smoching in dangerous areas.

- Protecting all electrical equipment from humidity, moisture and water.

- Providing workers with necessary personal protective equipment (gloves, masks, safety shoes).

- Using effective ventilation and exhaust systems to eliminate hazardous vapours or fumes; where these are not fully effective, using appropriate personal protective equipment.

- Performing regular medical examinations, etc.

We suggest a reassessment of activity sector after the implementation of these measures and to compare this result with that obtained at first evaluation in order to verify the effectiveness of measures for prevention and protection implemented.

General idea that shows the importance of this system of occupational risks assessment consists in the fact that nothing can be achieved without a motivated/interested staff. The new methods, technologies, tools, techniques can be implemented only with the people and for people. It is particularly important that any technique or method to be presented by such a way as to appear in the eyes of the staff as a useful tool, and not as a tool for monitoring employee activity or suppressing it. According to legislation in safety and health, all employers should periodically assess the occupational risks. The main goal of the occupational risk assessment is to protect workers, helping to maintain competitiveness and enterprise productivity.

\section{Conclusion}

Today, in the European countries more then $95 \%$ of the companies are small and medium-sized enterprises (SMEs) and majority of the European Union employees work in these companies. In Romania just few SMEs develop proper risk measure and cover mechanisms. Regarding our companies the RMP in the majority of annual report of Top 15 BSE (Bucharest Stock Exchange) Romanian listed companies $60 \%$ are in an incipient stage of implementation, only $40 \%$ of this Top 15 companies have already defined their objectives regarding risk management or already have an integrated system of risk management (Blidisel et al., 2008). 
In this paper we describe the SMEs knowledge and knowledge management key processes, the professional risk assessment as part of SMEs risk management process and we present a method to built a knowledge based system to assess the profesional risks, starting from a SMEs knowledge management framework.

This work realized at the UPB - PREMINV Research Centre, in University "Politehnica" of Bucharest, is focusing on a university - small and medium-sized enterprise partnership. The validation of this methodology by a case study in the PROGPROC project (CNMP 11014/2007 - between 2007-2010) is to create a support system for resources planning and programming activities according to manufacturing processes management in virtual organizations.

We intend that our future work in this area includes building other knowledge bases to evaluate eventually other SMEs activities who involve risks.

\section{References}

Baetens, K. (2008). Risk assessment in small and medium-sized enterprises (SMEs): UEAPME's point of view. Magazine 11 - Healthy Workplaces. Good for you. Good for bussiness, Magazine of the European Agency for Safety and Health at Work, printed in Belgium, ISSN 1608-4144

Blidisel, R.; Popa, A. \& Farcane, N. (2008). Disclosure Level of Risk Management Information: the Case of Romanian Companies, Annals of DAAAM for 2008 \& Proceedings of the $19^{\text {th }}$ International DAAAM Symposium, October $22^{\text {th }}-25^{\text {th }}$, B. Katalinic (Ed.), published by DAAAM International, Vienna, Austria, pp. 115-116, ISSN 1726-9679, ISBN 3-901509-58-5

Botezatu, C.; Botezatu, C.P. \& Carutasu, G. (2008). Conformity Issues for Health and Safety at Work - Part of Integrated Management Systems, Annals of DAAAM for 2008 \& Proceedings of the $19^{\text {th }}$ International DAAAM Symposium, October $22^{\text {th }}-25^{\text {th }}$, B. Katalinic (Ed.), published by DAAAM International, Vienna, Austria, pp. 151-152, ISSN 1726-9679, ISBN 3-901509-58-5

Doval, E. \& Stoica, M. (2008). Risk Control Management Concerning Strategic Resources by Using Subtle Sets Theory. Academic Journal of Manufacturing Engineering, Vol. 6, No. 2/2008, pp. 43-48, ISSN 1582-9596

Dragoi, G.; Rosu, S.M.; Guran, M.; Cotet, C.E. \& Rosu, L. (2007). A Knowledge Management Methodological View to Improve Virtual Product Development, Chapter 19 in DAAAM International Scientific Book 2007, B. Katalinic (Ed.), DAAAM International, Vienna, Austria, pp. 199-212, ISSN 1726-9687, ISBN 3-901509-60-7

Fink, K. \& Ploder, C. (2006). The Impact of Knowledge Process Modeling on Small and Medium-sized Enterprises, Proceedings of the I-KNOW'06, J.UCS., Tochtermann, K. \& Maurer, H. (Eds.), pp. 47-51, September $6^{\text {th }}-8^{\text {th }}$, Graz, Austria, ISSN 0948-695x

Fink, K. \& Ploder, C. (2007). Knowledge Process Modelling in SME and Costefficient Software Support - Theoretical Framework and Empirical Studies, in Khosrow-Pour, M. (Ed.), Managing Worldwide Operations and Communications with Information Technology, IGI Publishing, Hershey, 2007, pp. 479-484, ISBN 978-1-59904-929-8 
Heinrich, L. \& Lehner, F. (2005). Informationsmanagement, Oldenbourg Verlag, Munchen/Wien, ISBN 3-486-57772-7

Nonaka, I. \& Takeuchi, H. (1995). The Knowledge-Creating Company: How Japanese Create the Dynamics of Innovation, Oxford University Press, New York, ISBN 0-19-509269-4

Nunes, M.; Annansingh, F.; Eaglestone, B. \& Wakefield, R. (2006). Knowledge Management Issues in Knowledge-Intensive SMEs. Journal of Documentation, Vol. 62, No. 1/2006, pp. 101-119, ISSN 0022-0418

Ploder, C. \& Fink, K. (2007). An Orchestration Model for Knowledge Management Tools in SMEs, Proceedings of the I-KNOW'07, J.UCS., Tochtermann, K. \& Maurer, H. (Eds.), pp. 176-184, $3^{\text {rd }}-5^{\text {th }}$ September, Graz, Austria, ISSN 0948$695 \mathrm{x}$

Porter, M. (2001). Strategy and Internet. Harvard Business Review, Vol. 79, no. 3/2001, pp. 62-78, ISSN 0017-8012

Rosu, S.M.; Dragoi, G.; Guran, M. \& Cotet, C.E. (2006). Knowledge Management in the CESICED Platform to Improve Collaborative Product Development, Annals of DAAAM for 2006 \& Proceedings of the $17^{\text {th }}$ International DAAAM Symposium, November $8^{\text {th }}-11^{\text {th }}$, B. Katalinic (Ed.), published by DAAAM International, Vienna, Austria, pp. 351-352, ISSN 1726-9679, ISBN 3-901509$57-7$

Rosu, S.M.; Dragoi, G., Draghici, A. \& Guran, M. (a2008). Transfer \& Capitalization Knowledge Management Support for Knowledge Applications Development in the Enterprise Business Intelligence, Chapter 57 in DAAAM International Scientific Book 2008, B. Katalinic (Ed.), DAAAM International, Vienna, Austria, pp. 673-684, ISSN 1726-9687, ISBN 978-3-901509-66-7

Rosu S.M.; Guran, M. \& Dragomirescu, C. (b2008). Expert System for Information System Risk Estimate at the Enterprise Level, Annals of DAAAM for 2008 \& Proceedings of the $19^{\text {th }}$ International DAAAM Symposium, October $22^{\text {th }}-25^{\text {th }}$, B. Katalinic (Ed.), published by DAAAM International, Vienna, Austria, pp. 1191-1192, ISSN 1726-9679, ISBN 3-901509-58-5

Rosu, S.M.; Dragoi, G. \& Guran, M. (2009). A Knowledge Management Scenario to Support Knowledge Applications Development in Small and Medium Enterprises. Advances in Electrical and Computer Engineering, Vol. 9 (16), No. $1 / 2009$, pp. 8-15, ISSN 1582-7445 (print), ISSN 1844-7600 (on-line)

Vasilescu, G.D.; Plesea, V. \& Baciu, C. (2008). Establishing the Acceptable Risk Level in Occupational Accidents and Diseases Based on a Formal Analysis. Environmental Engineering and Management Journal, Vol. 7, No. 6, pp. 785789, ISSN: 1582-9596

Yule, S.; Flin, R. \& Murdy, A. (2007). The Role of Management and Safety Climate in Preventing Risk-Taking at Work. International Journal of Risk Assessment and Management, Vol. 7, No. 2, pp. 137-151, ISSN 1466-8297

*** European Agency for Safety and Health at Work (a2007). Risk Assessment Essentials, printed in Nurnberg, Germany

*** European Agency for Safety and Health at Work (b2007). The Business Benefits of Good Occupational Safety and Health, Fact sheet 77, printed in Belgium 